\title{
The scientific studies on smart grid in selected European countries
}

\author{
Serhat Orkun Tan ${ }^{1, *}$, Ilker Türker ${ }^{2}$, and Türker Toku ${ }^{3}$ \\ ${ }^{1}$ Karabuk University, Department of Electrical and Electronics Engineering, Karabuk, Turkey \\ ${ }^{2}$ Karabuk University, Department of Computer Engineering, Karabuk, Turkey \\ ${ }^{3}$ Karabuk University, Department of Information Processing Management, Karabuk, Turkey
}

\begin{abstract}
Smart grid is a power system consisting of many transmission and distribution systems subjected to an automation which are efficient, reliable and coordinated with each other. As a nature friendly technology, Smart grid come into prominence due to the increasing energy consumption and limited renewable energy sources around the world. In the near future, the use of renewable energy sources is not expected to grow rapidly; but the transmission and distribution systems will be enhanced by Smart grid technologies. Considering these significant benefits, the studies have been increased on Smart grid technologies to meet the energy requirement in each country. Herewith, the aim of this study is to analyse the scientific studies in developed European countries such as Italy, Germany, United Kingdom, France and Spain to find out the increment rate of the importance devoted to the Smart grid technologies in academicals manner. The scientific researches on Smart grid are achieved from the Web of Science database and the statistical analysis have been made by utilizing proper SQL queries in combination with Excel Power Pivot for these countries. The correlation between the scientific studies on smart grid and the virtual smart grid applications are also outlined for each selected country.
\end{abstract}

\section{Introduction}

The predictions for future energy consumption and the calculations for the amounts of natural reserves remaining in the world and their consumption times are made in seminars and symposiums which are organized all over the world due to increasing energy demand. According to the scenario prepared by the International Energy Agency (WEO2016), the world's energy needs continue to grow and a 30\% rise in global energy demand to 2040 means an increase in consumption for all modern fuels. But global aggregates mask various trends and significant changes between fuels. Additionally in 2040 hundreds of millions of people will be left without basic energy services [1]. From this point of view, this future concerns require the application of methods such as smart grid to achieve safer and sustainable energy [2-3].

Smart grid (SG) networks include smart meters and monitoring systems to monitor and update the electricity networks and provide user safety while ensuring consistently reliable

\footnotetext{
* Corresponding author: serhatorkuntan@karabuk.edu.tr
} 
and high quality distribution [4-6]. Adaptation to existing technologies, commercial appealingness, continuous developments and investments are significant reasons that deployed SG all over the world at different rates. Implementing SG across countries that faced huge demand and aging electrical infrastructure is crucial to make the energy grids more reliable, efficient and sustainable in these countries. In addition, SG is a significant factor in promoting the utilization of technologies including electric vehicles and renewable energy sources such as geothermal energy, wind energy and solar heat and power [3, 7-10]. The importance given to the applications on SG is necessary for countries when taking into account economic and environmental interests for a near future [11-14]. The modernization of the electricity network with new installations is also a reason for the rapid development of $\mathrm{SG}$ especially in various regions of the world $[15,17]$. For the most efficient use of energy, the need for SG all around the world is increasing day by day in terms of energy management and integration with renewable energies [18].

Considering these important contributions to the energy sector, many researchers around the world make scientific studies that shed light on SG applications. A study on SG technologies in developing countries obtained the data from ISI Web of Knowledge and presented the published items on SG for 20 years up to 2012 [3]. As can be seen from Figure 1, there were fewer than 50 academic studies before 2008. After this year smart grid technology has become a hot issue and a very rapid increase in publications has been observed in 2011. As a result, SG technology is a widespread topic, and studies, applications and investments are expected to increase rapidly in the future.

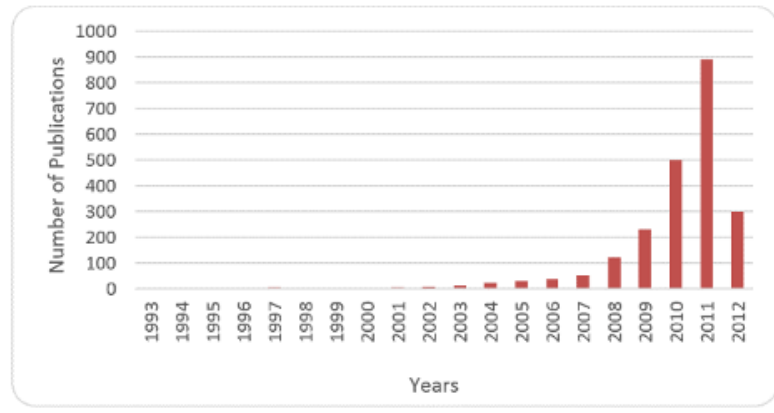

Fig. 1. Published items on smart grid for 20 years up to 2012.

\section{Methodology}

Depending on the data at Web of Science database, automatic retrieval of information was made by a data retrieval method which used a data retriever program to read the clipboard periodically if any new data has been placed therein. Through the program, each new data search is checked whether the pre-determined criteria can be met. In addition, if the program meets the criteria, it initiates data retrieval by performing a web based search based on the data. If the criteria are not met, the program will not perform data retrieval. [19]. Data extraction from the Web of Science database and statistical analysis with the SQL server management studio is done through the operation logic of the Automatic Data Collection Method. As keywords to focus our study, we entered the words "smart grid" and also as a compound word of "smart grid" to the Web of Science database for not to skip any publications in this area. The statistical distributions of the researches made on the smart grid and the analysis values of the data were transferred to Excel Power Pivot and the analysis results were visualized. 


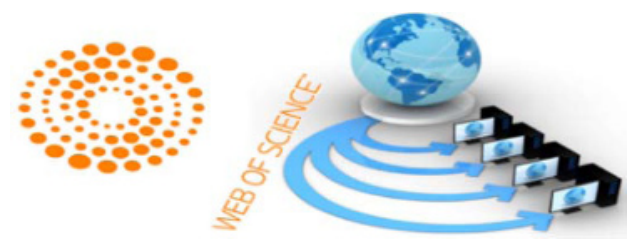

Fig. 2. The data retrieval schematic diagram of selected countries from Web of Science

\section{Results and discussion}

Initiatives on SG have been attracted considerable attention in many countries around the world. The production and distribution of energy varies due to the increase in energy demand, reliability, and environmental concerns. Consequently, organizations around the world are searching for more effectual and reliable methods to energy production and distribution. The "smart grid" has revealed as an operative way to manage the peak load of energy, power supply integration from renewable energy sources and increase consumer control over domestic usage of energy [12, 20-22]. UK, Germany, Italy, Spain and many other developing countries are adopting SG technology to prevent energy pilferage.

In recent years, many countries have invested significant amounts in SG technology and the global market is expected to grow continuously for ten years. The cumulative data for the budget of SG projects in Germany, Italy, France, Spain and UK is presented in Figure 3. The data in the figure is assumed as all the budget of related countries is allocated in the starting year. The total budget is calculated by the sum of research and development (R\&D) and demonstration and deployment (D\&D) budgets of smart grid projects for the countries.

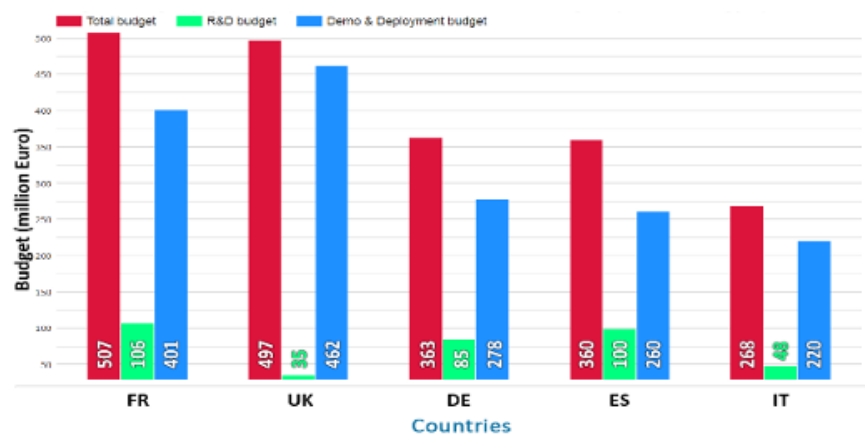

Fig. 3. The cumulative data for the budget of Smart grid projects of the selected countries [23].

As seen from Figure 3, France and the UK are the countries with the highest investment in SG projects. The highest budget was allocated by France and Spain to the R\&D and especially Spain comes first in ratio by allocating nearly $30 \%$ of its total budget to these projects. On the other hand, UK is leading by allocating more than $90 \%$ of its budget to the D\&D but it takes also the last place by 35 million euro budget to the R\&D. Generally, Figure 3 can be evaluated as, all countries give priority to allocate most of their budgets to the D\&D where France, Spain and almost Germany give more importance to the R\&D for Smart grid projects. Considering the budgets allocated to SG projects, Figure 4 shows the linkages of cooperation in European multinational projects. Approximately 170 projects carried out by multinational consortia and collaboration of European countries on these projects is presented in Figure 4 [23]. 

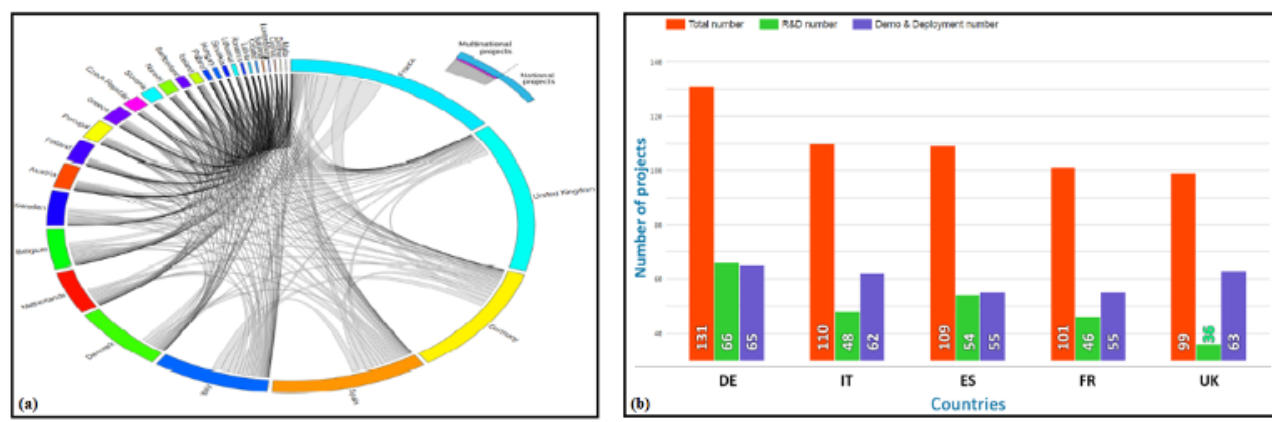

Fig. 4. a) The linkages of cooperation in European multinational projects, b) The total smart grid project numbers of selected countries [23]

The most striking point in Figure 4.a is the multinational projects region that, French, Germany, Spain and Italy allocated nearly $50 \%$ of their budget to the multinational projects where UK allocated a shoestring budget to these projects. As mentioned in Figure 3, UK allocated $90 \%$ of its budget to the D\&D and this can also be explained in Fig.4.a as UK allocated many of its budget to the national SG D\&D projects. This situation is also verified in Fig.4.b which indicates the total SG project numbers of selected countries. As seen Figure 4.b, apart from UK the other selected countries have almost the same number of R\&D and D\&D projects. The budget of multinational projects on SG for these countries are also proportional to the project numbers on SG projects. Considering R\&D projects on SG, UK has least project numbers and this can be explained by its budget on R\&D projects and also its budget on multinational projects. All in all, the budget allocated for D\&D projects is more than the budget for $\mathrm{R} \& \mathrm{D}$ projects when considering the total budget and number of projects together. It is important to reveal the relation between the academic and scientific studies on the SG technology and the budgets and project numbers that countries allocate to this technology in order to see how the applications interact with the scientific studies in this area. From this point of view, Figure 5 indicates the number of publications that each selected countries have been made for 8 years. As seen from Figure 5, the average number of publications increase by years and this is also in direct proportion to the developments, budgets and projects on the SG technology. Considerable number of publications have been made during 2009-2016 period as SG technology has become a hot issue around the world.

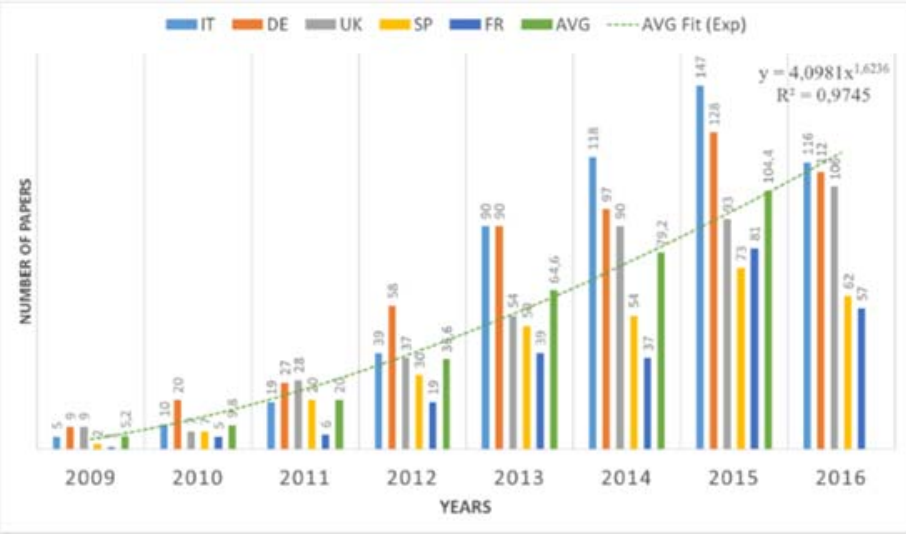

Fig. 5. The number of publications that each selected countries by years.

It is clearly seen in Figure 6.a that the same rate of increment is observed in this time period in the worldwide publications. 2015 was a very efficient year for both Europe and 
world when taking into account the number of publications on SG. It was also observed that there were very few publications on SG before 2008, when the publications made around the world were evaluated since 1975 . Figure 6.b presents the number of publications of the most publishing countries in the world from 1975 to this time. USA and China are far ahead of other countries in terms of the number of publications as shown in Figure 6.b.
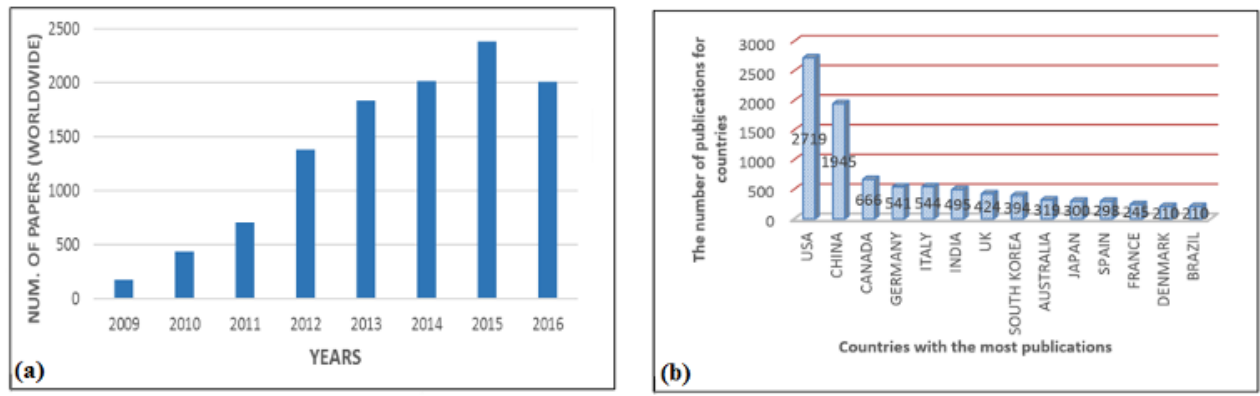

Fig. 6. a) The total number of publications all over the world by years, b) The distribution of the top publishing countries worldwide

In general, it can be assumed that the numbers of the publications of these five prominent European countries are similar to the project numbers and budgets allocated to this area. Especially when the numbers of publications and project numbers examined, it can be seen as, the publication numbers of the UK are slightly ahead of their project numbers and this also changes the ranking in this sense. However, the fact that the numbers are close to each other makes it possible to assume that the scientific studies or publications increase with increasing applications or projects in countries basis. A quantitative way to abstract the relation between data series is extracting correlations between them. Considering the total numbers of budgets (B), projects (PR) and publications (PU) for the selected countries, we calculate the correlations as: B-PR: -0.537 , B-PU: -0.617 and PR-PU: +0.603 . Here, the only positively correlated pair is projects and publication counts. But elaborating the components of the first two parameters as R\&D and D\&D subsections, the correlations are extracted as following: BRD-PRRD: +0.536 , BRD-PU: -0.621 , PRRD-PU: +0.305 . As seen, for R\&D data, budget and project pair becomes positively correlated, while the correlation for projectspublications decrease and budget-publication remains same. Lastly, evaluating the data for only D\&D sections, we find correlations as: BDD-PRDD: -0.046, BDD-PU: - 0.42 , PRDDPU: +0.914 . These results show that project and publication counts are very strongly correlated for the D\&D data. Such a strong correlation close to 1 is an indicator of a possible relation between publications funding between the D\&D budget.

\section{Conclusions}

The governments of many developed countries have significant critical objectives as economic growth, environmental sustainability and energy security. The SG is one of the critical way to achieve these objectives. Thus, European developed countries such as Germany, UK, France, Spain and Italy have regional and multiregional projects and allocate budgets to SG. In addition to this SG technology in these countries is also supported by scientific or academic studies. In this study, the correlation between the scientific studies and the projects and allocated budgets have been investigated by comparing the number of studies, the number of projects and total allocated budgets of the related European countries. It has been observed that the allocated budgets, projects and scientific studies increase years by years and vary in direct proportion to each other. This increment is also similar in countries 
all over the world. Consequently, it is clear that the importance given to SG technology have increased each passing year by the projects and the allocated budgets and this increase is supported by the increment of scientific or academic studies made in the selected leading European countries.

We thank to Scientific Research Projects (BAP) Coordinatorship of Karabuk University for funding this study with project code of KBÜBAP-17-YD-230.

\section{References}

1. www.iea.org, “World Energy Outlook 2016”, International Energy Agency (IEA)

2. C. Cecati, C. Citro, P. Siano, IEEE Trans. Sustain. Energy 2 (4), 468-476 (2011)

3. M. Fadaeenejad, A. M. Saberian, M. Fadaee, M. A. M. Radzi, H. Hizam, M. Z. A. AbKadir, Renew Sust Energ Rev 29, 828-834 (2014)

4. S. Kaufmann, K. Künzel, M. Loock, Energy Policy 53, 229-239 (2013)

5. H. Gharavi, R. Ghafurian, Proceedings of the IEEE 99, 6, 917-921 (2011)

6. G. Rietveld, J. P. Braun, R. Martin, P. Wright, W. Heins, N. Ell, P. Clarkson, N. Zisky, IEEE T Instrum Meas 64 (6), 1355-1363 (2015)

7. N.C. Batista, R. Melício, J.C.O Matias, J.P.S. Catalão, Energy 49 (1), 306-315 (2013)

8. D.S. Markovic, D. Zivkovic, I. Branovic, R. Popovic, D. Cvetkovic, Renew Sust Energ Rev 24, 566-577 (2013)

9. A.S. Malik, M. Bouzguenda, Energy 54 (1), 365-371 (2013)

10. M. Alonso, H. Amaris, C. Alvarez-Ortega, Expert Systems with Applications 39 (55), 13-22 (2012)

11. J. Gao, Y. Xiao, J. Liu, W. Liang, C. L. P. Chen, Future Generation Computer Systems 28, 391-404 (2012)

12. https://www.smartgrid.gov/files/Global_Smart_Grid_Federation_Report.pdf

13. M. M. Abdullah, B. Dwolatzky, Proceedings of IEEE AFRICON (2009)

14. https://www.eia.gov/analysis/studies/electricity/pdf/intl_sg.pdf

15. M. G. Simões, IEEE Transactions on Industry Applications 48 (2), 1154-1162 (2012)

16. D. Mah, J. Vleuten, P. Hills, J. Tao, Energy Policy 49, 204-216 (2012)

17. J. Yuan, J. Shen, L. Pan, C. Zhao, J. Kang, Renew Sust Energ Rev 37, 896-906 (2014)

18. N.S. Nafi, K. Ahmed, Mark A. Gregory, M. Datta, J Netw Comput Appl 76, 23-36 (2016)

19. S. E. Waggoner, US8762401 B2 (2010)

20. N. Iqtiyanillham, M. Hasanuzzaman, M. Hosenuzzaman, Renew Sust Energ Rev 67, 776-790 (2017)

21. http://ses.jrc.ec.europa.eu/sites/ses/files/documents/smart_grid_projects_in_europe_les sons_learned_and_current_developments.pdf

22. H. Farhangi, IEEE Power Energy Mag 8 (1), 18-28 (2010)

23. http://ses.jrc.ec.europa.eu 